\section{Cureus}

Received 04/09/2019

Review began 04/13/2019

Review ended 04/19/2019

Published 04/25/2019

\section{(c) Copyright 2019}

Pendharkar et al. This is an open access article distributed under the terms of the Creative Commons Attribution License CC-BY 3.0., which permits unrestricted use, distribution, and reproduction in any medium, provided the original author and source are credited.

\title{
Granular Cell Pituitary Tumor in a Patient with Multiple Endocrine Neoplasia-1
}

\author{
Arjun V. Pendharkar ${ }^{1}$, Chieh-Yu Lin ${ }^{2}$, Donald E. Born ${ }^{3}$, Andrew R. Hoffman ${ }^{4}$, Robert L. \\ Dodd $^{1}$
}

1. Neurosurgery, Stanford University School of Medicine, Stanford, USA 2. Pathology \& Immunology, Washington University in St. Louis, St. Louis, USA 3. Pathology, Stanford University School of Medicine, Stanford, USA 4. Internal Medicine - Diabetes \& Endocrinology, Stanford University School of Medicine, Stanford, USA

$\square$ Corresponding author: Arjun V. Pendharkar, apendhar@stanford.edu Disclosures can be found in Additional Information at the end of the article

\section{Abstract}

Multiple endocrine neoplasia type 1 (MEN-1) is an autosomal dominant disorder characterized by parathyroid, pancreatic islet, and pituitary tumors. Approximately $40 \%$ of MEN-1 patients harbor a pituitary adenoma. Separately, granular cell tumors (GCTs) of the sellar/parasellar region are an exceedingly rare clinical entity with less than 100 reported cases in the literature. These slow-growing, often asymptomatic lesions are difficult to diagnose and may mimic pituitary adenoma, Rathke cleft cyst, or other sellar/supra-sellar pathology. There is no known association with MEN-1 or any other familial syndrome. A 36-year-old neurologically normal woman with known MEN-1 underwent a screening magnetic resonance imaging (MRI) scan which revealed a $10 \mathrm{~mm}$ x $6 \mathrm{~mm}$ x $7 \mathrm{~mm}$ sellar/suprasellar lesion. She underwent endoscopic endonasal transsphenoidal resection. Subsequent neuropathological analysis was consistent with GCT of the pituitary gland. Here we describe the first report to our knowledge of a GCT of the pituitary gland occurring in a patient with MEN-1.

Categories: Endocrinology/Diabetes/Metabolism, Neurosurgery, Oncology

Keywords: multiple endocrine neoplasia type 1, men-1, granular cell tumor, pituitary tumor

\section{Introduction}

Multiple endocrine neoplasia type 1 (MEN-1) is an autosomal dominant disorder characterized by parathyroid, pancreatic islet, and pituitary tumors. Approximately $40 \%$ of all MEN-1 patients harbor a pituitary adenoma [1].

Separately, granular cell tumors (GCTs) of the sellar/suprasellar region are an exceedingly rare clinical entity with less than 100 reported cases in the literature [2-4]. These slow-growing, often incidental and asymptomatic lesions are difficult to diagnose and may mimic pituitary adenoma [5], Rathke cleft cyst [6], or other sellar/supra-sellar pathology [7]. There is no known association of GCTs with MEN-1 or any other familial syndrome.

Here we describe the first report to our knowledge of a GCT of the pituitary gland occurring in a patient with MEN-1.

\section{Case Presentation}

The patient is a 36-year-old woman with MEN-1 status-post parathyroidectomy in whom a 


\section{Cureus}

screening magnetic resonance imaging (MRI) scan demonstrated a $10 \mathrm{~mm}$ x $6 \mathrm{~mm}$ x $7 \mathrm{~mm}$ hypoenhancing T1 and T2- intermediate, contrast enhancing sellar/suprasellar lesion displacing and compressing the optic chiasm superiorly. The imaging was felt to be atypical for pituitary adenoma, and it remained unclear whether the lesion was involved with, or separate from the pituitary infundibulum (Figures $1 A-1 D$ ). The patient was neurologically normal with intact visual fields and normal endocrine function.
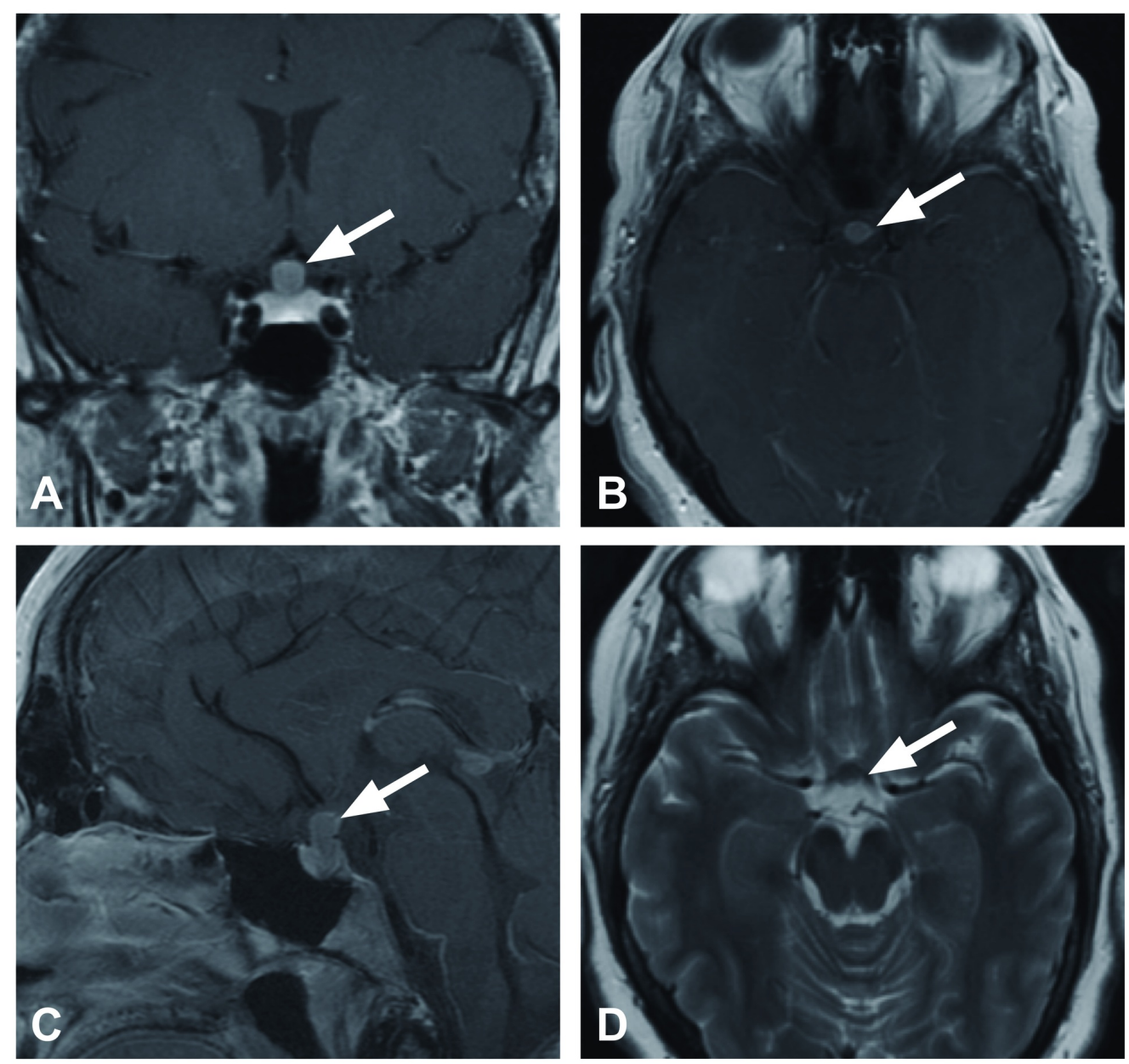

\section{FIGURE 1: Preoperative magnetic resonance imaging.}

Preoperative magnetic resonance imaging demonstrates a hypoenhancing T1 and T2 intermediate lesion arising from the postero-superior aspect of the pituitary gland. The sellar-suprasellar lesion approximately $10 \mathrm{~mm} \times 6 \mathrm{~mm} \times 7 \mathrm{~mm}$ enhances with gadolinium administration. A) Coronal T1 postgadolinium, B) axial T1 post-gadolinium, C) sagittal T1 post-gadolinium, D) axial T2.

Given the possibility of future visual loss and the benefit of tissue diagnosis and given the unclear MRI findings, the patient elected for endoscopic endonasal transsphenoidal resection. Intraoperatively, a mass was clearly delineated posterior to the pituitary gland, adherent to the arachnoid tissue, and intraoperative frozen section confirmed neoplastic tissue. Gross total resection was achieved. The patient's postoperative course was significant for development of panhypopituitarism and she was discharged on a standing regimen of cortisol, levothyroxine, and desmopressin.

Subsequent neuropathological analysis was consistent with GCT of the pituitary gland (Figures $2 A-2 D)$. Histological sections demonstrated proliferation of large ovoid and spindle cells in 


\section{Cureus}

nests with abundant eosinophilic cytoplasmic granules. Immunohistochemistry revealed S100, chromogranin A, and thyroid transcription factor 1 (TTF-1) uniformly positive reactivity and variably positive epithelial membrane antigen (EMA) staining.
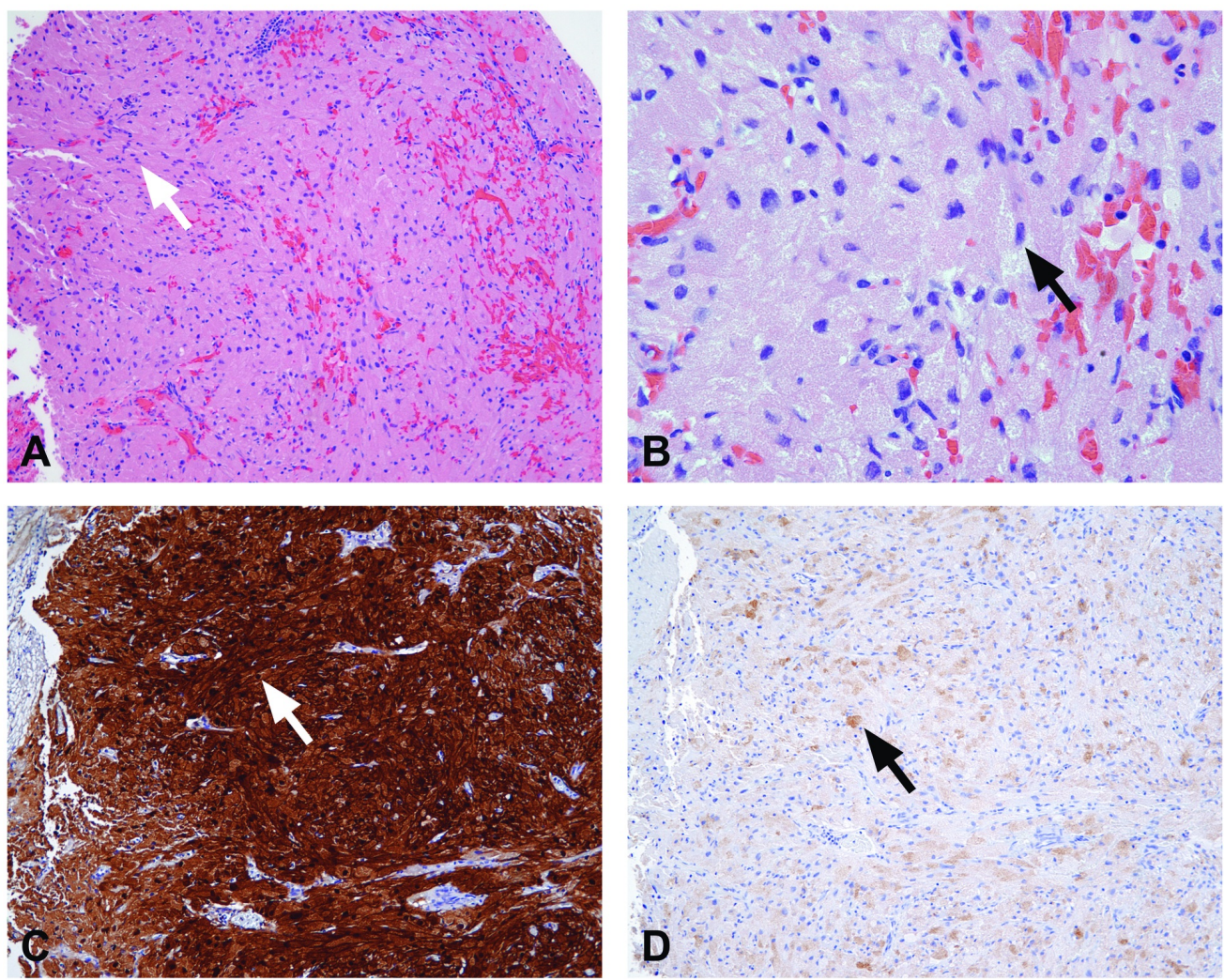

\section{FIGURE 2: Neuropathological analysis.}

Morphologic and immunophenotypic characteristics are consistent with granular cell tumor of the pituitary gland. Proliferation of ovoid and spindle cells in loose nests and fascicles with indistinct cytoplasmic borders. Abundant eosinophilic granules are present in the cytoplasm while nuclei exhibit moderate atypia and are variable in size. A) Granular cell tumor 10x, B) granular cell tumor 40x, C) S100 10x, D) epithelial membrane antigen 10x.

At one year follow-up, the patient was doing well clinically, neurologically normal with full visual fields maintained on a stable pituitary hormonal replacement. The MRI at that time demonstrated expected postoperative changes but no evidence of residual or recurrent disease (Figures 3A-3D). 


\section{Cureus}
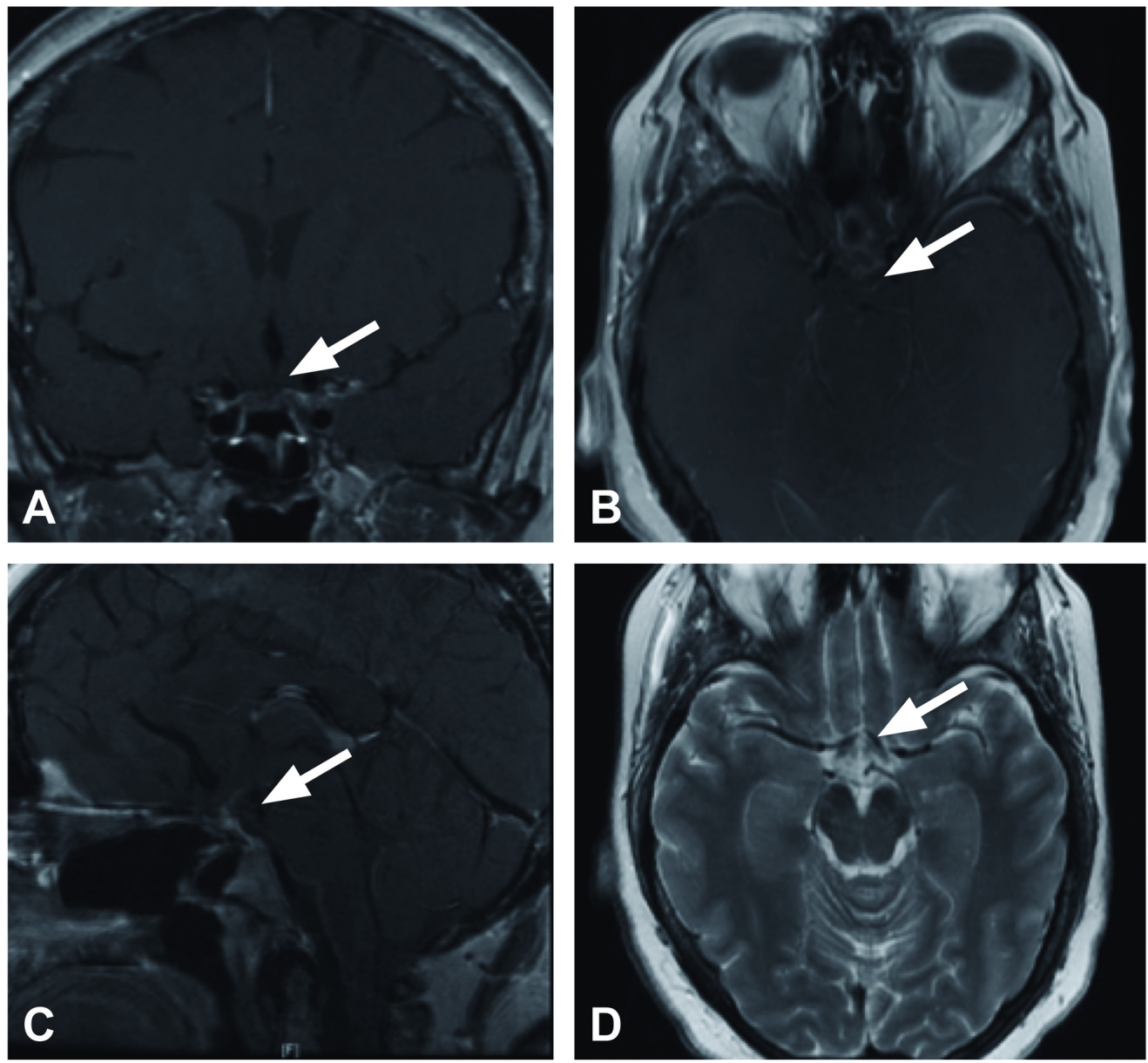

\section{FIGURE 3: Postoperative magnetic resonance imaging at six months.}

Magnetic resonance imaging at six months with post-surgical changes and no residual or recurrent disease. A) Coronal T1 post-gadolinium, B) axial T1 post-gadolinium, C) sagittal T1 postgadolinium, D) axial T2.

\section{Discussion}

Boyce and Beadles first reported an 'accessory body taking origin from the infundibulum' in 1893 and Sternberg first identified a granular cell tumor in 1921 [8-9]. These slow-growing, often asymptomatic lesions have previously been referred to as choristoma, pituicytoma, myoblastoma, and infundibuloma reflecting the confusion surrounding posterior pituitary and infundibular pathology. Currently GCTs are defined as WHO Grade 1 lesions originating from pituicytes and are a distinct clinical entity from pituicytoma [10]. Radiographically GCTs are most commonly hyperattenuated to cerebral parenchyma on computed tomography (CT) with a homogenous pattern of enhancement. The MRI reveals hypointense or isointense T1 signal and isointense T2 signal. GCTs tend to homogenously enhance with gadolinium contrast administration [11]. The histological features include nests of large cells with granular eosinophilic cytoplasm [12].

Although less than 100 cases have been reported in the literature, autopsy studies suggest that GCTs may exist in up to $9 \%$ of patients without any symptoms [13]. The most common 
presenting symptoms in clinical series are visual disturbance and headache and GCTs may mimic adenoma, Rathke's cleft cyst or present with endocrine disturbances including panhypopituitarism or acromegaly [2, 6, 14-15]. Surgical resection is the definitive treatment and patients most commonly experience postoperative pituitary dysfunction due to infundibular involvement of the lesion [7, 16].

Up to $40 \%$ of patients with MEN-1 harbor a pituitary adenoma. Prolactinomas represent the overwhelming majority of cases although growth hormone, adrenocorticotropic hormone (ACTH), co-secreting, and nonfunctioning adenomas are well described. Pituitary adenomas in MEN-1 are larger at presentation and more histologically aggressive than their sporadic counterparts $[1,17]$. There are no prior reports of pituitary lesions other than adenoma in MEN1 and GCTs are not associated with any familial or syndromic diseases. Interestingly, Cusick et al. in 1982 reported a 'granular-cell pituicytoma' now defined as GCT in a multiple endocrine neoplasia type 2 (MEN-2) patient [18]. Schultz et al. in 2001 reported a true pituicytoma in a patient with unproven but high phenotypic suspicion for MEN-1 [19].

We report the first case of GCT occurring in a patient with MEN-1. In addition to the classic pituitary adenomas, pancreatic neuroendocrine and parathyroid tumors, MEN-1 is also loosely associated with adrenal cortical tumors, pheochromocytoma, lipoma, angiofibroma,

collagenoma, and meningioma. Additionally, Hall et al. recently reported bilateral ovarian granulosa cell tumors in a patient with a rare c.654 + $1 \mathrm{G}>\mathrm{A}$ MEN1 mutation [20]. We conducted genetic testing on our patient, who was found to harbor a different MEN-1 mutation (K517 c.1549A $>$ T) resulting in a nonsense codon. The question remains, however, if this was a sporadic occurrence or a rare manifestation of MEN-1. In the former scenario, our patient will require ongoing surveillance for development of a pituitary adenoma.

\section{Conclusions}

We describe the first report to our knowledge of a GCT of the pituitary gland occurring in a patient with MEN-1.

\section{Additional Information \\ Disclosures}

Human subjects: Consent was obtained by all participants in this study. Conflicts of interest: In compliance with the ICMJE uniform disclosure form, all authors declare the following:

Payment/services info: All authors have declared that no financial support was received from any organization for the submitted work. Financial relationships: All authors have declared that they have no financial relationships at present or within the previous three years with any organizations that might have an interest in the submitted work. Other relationships: All authors have declared that there are no other relationships or activities that could appear to have influenced the submitted work.

\section{References}

1. Thakker RV, Newey PJ, Walls GV: Clinical practice guidelines for multiple endocrine neoplasia type 1 (MEN1). J Clin Endocrinol Metab. 2012, 97:2990-3011. 10.1210/jc.2012-1230

2. Gagliardi F, Spina A, Barzaghi LR, Bailo M, Losa M, Terreni MR, Mortini P: Suprasellar granular cell tumor of the neurohypophysis: surgical outcome of a very rare tumor. Pituitary. 2016, 19:277-285. 10.1007/s11102-016-0704-7

3. Park SJ, Chang YH, Yang NR, Seo EK: Granular cell tumor in the pituitary stalk: a case report . Brain Tumor Res Treat. 2015, 3:60-63. 10.14791/btrt.2015.3.1.60

4. Shizukuishi T, Abe O, Haradome H, Fukushima T, Katayama Y, Sugitani M: Granular cell tumor of the neurohypophysis with optic tract edema. Jpn J Radiol. 2014, 32:179-182. 


\subsection{7/s11604-013-0279-4}

5. Sasazawa DT, Reis F, Queiroz LS, Rogerio F, Garmes HM: Granular cell tumor (GCT) mimicking a nonsecreting anterior pituitary adenoma. Arq Neuropsiquiatr. 2015, 73:1045. 10.1590/0004-282X20150157

6. Mumert ML, Walsh MT, Chin SS, Couldwell WT: Cystic granular cell tumor mimicking Rathke cleft cyst. J Neurosurg. 2011, 114:325-328. 10.3171/2010.5.JNS1058

7. Cohen-Gadol AA, Pichelmann MA, Link MJ: Granular cell tumor of the sellar and suprasellar region: clinicopathologic study of 11 cases and literature review. Mayo Clin Proc. 2003, 78:567-573. 10.4065/78.5.567

8. Boyce R, Beadles CF: A further contribution to the study of the pathology of the hypophysis cerebri. J Pathol. 1893, 1:359-383. 10.1002/path.1700010310

9. Sternberg C: Ein choristom der neurohypophyse bei ausgebreiteten oedemen . Zentralbl Pathol Anat. 1921, 585-591.

10. Wolfe SQ, Bruce J, Morcos JJ: Pituicytoma: case report. Neurosurgery. 2008, 63:173-174. 10.1227/01.NEU.0000335084.93093.C8

11. Covington MF, Chin SS, Osborn AG: Pituicytoma, spindle cell oncocytoma, and granular cell tumor: clarification and meta-analysis of the world literature since 1893. Am J Neuroradiol. 2011, 32:2067-2072. 10.3174/ajnr.A2717

12. Policarpio-Nicolas ML, Le BH, Mandell JW, Lopes MB: Granular cell tumor of the neurohypophysis: report of a case with intraoperative cytologic diagnosis. Diagn Cytopathol. 2008, 36:58-63. 10.1002/dc.20646

13. Tomita T, Gates E: Pituitary adenomas and granular cell tumors. Incidence, cell type, and location of tumor in 100 pituitary glands at autopsy. Am J Clin Pathol. 1999, 111:817-825.

14. Losa M, Saeger W, Mortini P, Pandolfi C, Terreni MR, Taccagni G, Giovanelli M: Acromegaly associated with a granular cell tumor of the neurohypophysis: a clinical and histological study. Case report. J Neurosurg. 2000, 93:121-126. 10.3171/jns.2000.93.1.0121

15. Schaller B, Kirsch E, Tolnay M, Mindermann T: Symptomatic granular cell tumor of the pituitary gland: case report and review of the literature. Neurosurgery. 1998, 42:166-170.

16. Orning JL, Trembath DG, Zanation AM, Germanwala AV: Endoscopic endonasal approach for resection of infundibular granular cell tumor: case report and literature review. J Case Rep Med. 2013, 2:235775.

17. Trouillas J, Labat-Moleur F, Sturm N: Pituitary tumors and hyperplasia in multiple endocrine neoplasia type 1 syndrome (MEN1): a case-control study in a series of 77 patients versus 2509 non-MEN1 patients. Am J Surg Pathol. 2008, 32:534-543. 10.1097/PAS.0b013e31815ade45

18. Cusick JF, Ho KC, Hagen TC, Kun LE: Granular-cell pituicytoma associated with multiple endocrine neoplasia type. J Neurosurg. 1982, 56:594-596. 10.3171/jns.1982.56.4.0594

19. Schultz AB, Brat DJ, Oyesiku NM, Hunter SB: Intrasellar pituicytoma in a patient with other endocrine neoplasms. Arch Pathol Lab Med. 2001, 125:527-530.

20. Hall MJ, Innocent J, Rybak C: Bilateral granulosa cell tumors: a novel malignant manifestation of multiple endocrine neoplasia 1 syndrome found in a patient with a rare menin in-frame deletion. Appl Clin Genet. 2015, 8:69-73. 10.2147/TACG.S72223 